Article

\title{
Assessment of Snowfall Accumulation from Satellite and Reanalysis Products Using SNOTEL Observations in Alaska
}

\author{
Yang Song ${ }^{1}$, Patrick D. Broxton ${ }^{2}$, Mohammad Reza Ehsani ${ }^{1}$ (D) and Ali Behrangi ${ }^{1, *(D)}$ \\ 1 Department of Hydrology and Atmospheric Sciences, The University of Arizona, Tucson, AZ 85721, USA; \\ yangsong22@email.arizona.edu (Y.S.); rehsani@email.arizona.edu (M.R.E.) \\ 2 School of Natural Resources and the Environment, The University of Arizona, Tucson, AZ 85721, USA; \\ broxtopd@email.arizona.edu \\ * Correspondence: behrangi@email.arizona.edu
}

Citation: Song, Y.; Broxton, P.D.;

Ehsani, M.R.; Behrangi, A.

Assessment of Snowfall

Accumulation from Satellite and Reanalysis Products Using SNOTEL Observations in Alaska. Remote Sens. 2021, 13, 2922. https://doi.org/ $10.3390 /$ rs13152922

Academic Editor: Ralph R. Ferraro

Received: 4 June 2021

Accepted: 19 July 2021

Published: 25 July 202

Publisher's Note: MDPI stays neutral with regard to jurisdictional claims in published maps and institutional affiliations.

Copyright: (c) 2021 by the authors. Licensee MDPI, Basel, Switzerland. This article is an open access article distributed under the terms and conditions of the Creative Commons Attribution (CC BY) license (https:// creativecommons.org/licenses/by/ $4.0 /)$

\begin{abstract}
The combination of snowfall, snow water equivalent (SWE), and precipitation rate measurements from 39 snow telemetry (SNOTEL) sites in Alaska were used to assess the performance of various precipitation products from satellites, reanalysis, and rain gauges. Observation of precipitation from two water years (2018-2019) of a high-resolution radar/rain gauge data (Stage IV) product was also utilized to give insights into the scaling differences between various products. The outcomes were used to assess two popular methods for rain gauge undercatch correction. It was found that SWE and precipitation measurements at SNOTELs, as well as precipitation estimates based on Stage IV data, are generally consistent and can provide a range within which other products can be assessed. The time-series of snowfall and SWE accumulation suggests that most of the products can capture snowfall events; however, differences exist in their accumulation. Reanalysis products tended to overestimate snow accumulation in the study area, while the current combined passive microwave remote sensing products (i.e., IMERG-HQ) underestimate snowfall accumulation. We found that correction factors applied to rain gauges are effective for improving their undercatch, especially for snowfall. However, no improvement in correlation is seen when correction factors are applied, and rainfall is still estimated better than snowfall. Even though IMERG-HQ has less skill for capturing snowfall than rainfall, analysis using Taylor plots showed that the combined microwave product does have skill for capturing the geographical distribution of snowfall and precipitation accumulation; therefore, bias adjustment might lead to reasonable precipitation estimates. This study demonstrates that other snow properties (e.g., SWE accumulation at the SNOTEL sites) can complement precipitation data to estimate snowfall. In the future, gridded SWE and snow depth data from GlobSnow and Sentinel-1 can be used to assess snowfall and its distribution over broader regions.
\end{abstract}

Keywords: Alaska; SNOTEL; snowfall accumulation; IMERG; precipitation

\section{Introduction}

Accurate quantitative knowledge of the amount and distribution of precipitation, precipitation phase, and snowpack is important for global water cycle studies, hydrology, and water resource management. For example, rainfall and snowfall affect streamflow differently, as streamflow response to rainfall is almost immediate, while streamflow response to snowfall can be delayed by many months. In contrast to rainfall, snowfall can be accumulated as snowpack and can act as a natural reservoir, storing water in mountains and cold regions and forming an important water resource for warmer seasons. Accurate estimations of rainfall, snowfall, and snowpack amount and distribution are thus important. While snowmelt remains a critical source of freshwater for the world population [1,2], in a warming climate, snowpack amounts are being reduced $[3,4]$ and most precipitation may fall as rain instead of snow. However, snowfall is still the dominant form of precipitation in high latitudes [5-7]. 
Snowfall is most accurately measured using in situ observations. However, these in situ data are sparse at high latitudes and in snow dominated regions (including mountains), partly due to the expense and difficulty of their installation and maintenance. Rain gauges are often used as the ground truth for precipitation measurements, but they are not typically designed for snowfall measurement and they often have snowfall undercatch issues and may not be well maintained. Correction factors (CFs) are applied to correct for the underestimation of precipitation. CFs are often much larger and more uncertain for snowfall than rainfall and can be up to a factor of three in many regions [8-11]. It should be noted that the wind-induced snow transport process can result in heterogeneous distribution of snow-cover, as snow erosion may exist when exposed to strong wind and snow may be deposited when sheltered by wind [12-14]. Therefore, snowfall measurements can be affected by wind transportation.

Satellite data make it possible to estimate precipitation rates from space, with almost global coverage. However, the quality of precipitation retrieval, especially snowfall, from most satellites is relatively poor (e.g., $[15,16]$. The problem is worse at high latitudes, where light rain and snowfall produce weak signals for capture by sensors. Although CloudSat provides direct snow and light rainfall observations over high latitude regions with a signal sensitivity at around-28 dBZ, it faces issues such as signal saturation for intense precipitation, missing precipitation near the surface, a low frequency of observation, and relatively short temporal span [17]. Furthermore, the dynamic nature of surface emissivity over snow and ice surfaces makes it challenging to retrieve precipitation from passive microwave (PMW) sensors that are key to the global precipitation measurement (GPM) mission [18]. As a result, for example, the Integrated Multi-Satellite Retrievals for GPM (IMERG) product [19] uses geostationary infrared for precipitation retrieval within $60^{\circ} \mathrm{N} / \mathrm{S}$, but poleward of this region, where geostationary images are too oblique, no estimate from the satellite is provided. Due to the lack of quality PMW precipitation estimates at high latitudes, the Global Precipitation Climatology Project (GPCP) $[19,20]$ uses precipitation retrieval from the atmospheric infrared sounder (AIRS; [21]), although the relationship between infrared data and precipitation is not physically robust. To refine merged products, more efforts are needed to evaluate and compare the performance of the new generation of PMW precipitation products with AIRS and other infrared sensors at high latitudes [22,23]. However, performing this important task is difficult, due to the limited availability of quality in situ observations in high latitude regions.

In the cold season, many regions experience subfreezing temperatures for several days or months. Snowfall is accumulated during these periods, and snowmelt is negligible. This can create an opportunity to investigate other aspects of snow that can potentially help assess snowfall amount. For example, by using the mass property of snow, it is possible to use changes in snow mass to estimate snowfall accumulation within a certain accumulation period. Using the observation of mass change from the Gravity Recovery and Climate Experiment (GRACE), [24] calculated snowfall accumulation over cold regions in the northern hemisphere and used the values to assess two popular gauge-undercatch correction factors (CFs): Legates climatology (CF-L), utilized in GPCP, and Fuchs dynamic correction model (CF-F), used in the Global Precipitation Climatology Centre (GPCC) monitoring product [25]. The difference between the two CFs can exceed $50 \%[24,26]$, so selection of the more accurate $\mathrm{CF}$ is important. Their results showed a greater consistency between GRACE-based snow accumulation estimates and GPCC-F (GPCC corrected by CF-F) than GPCC-L (GPCC corrected by CF-L), in terms of both the amount and spatial pattern of snowfall accumulation over the studied regions. However, GRACE offers a relatively coarse temporal (i.e., about a month) and spatial (about $300 \mathrm{~km}$ ) resolution that limits its application in several places. Furthermore, the application of GRACE over mountainous regions and glaciers is complicated due to the coarse resolution and issues related to ice age rebound and glacier dynamics [27].

Another approach could be to use the observation of snow water equivalent (SWE), because during the snow accumulation period SWE and snowfall are well connected 
(Broxton et al., 2016a). Snow water equivalent refers to the amount of snow in the snowpack and is often used for the unit of snowfall. Therefore, high quality observations of SWE can be valuable to assess snowfall. Ref. [28] utilized SWE estimates from the Airborne Snow Observatory (ASO) [29] over two mountainous basins in California; while [30] used SWE values from the University of Arizona SWE product (UA-SWE) [4,31] over the northern CONUS to assess snowfall products. Ref. [32] also used estimates of snowfall and SWE from the Advanced Microwave Scanning Radiometer (AMSR-E) instrument to assess the consistency in snow products. However, due to large errors and shortcomings in the retrieval of both SWE and snowfall from AMSR-E, neither of these products were found to be effective for the assessment of the other.

In this work, we used in situ measurements of SWE and snowfall at SNOTEL stations in Alaska to assess a variety of remotely sensed, gauge-based, and reanalysis precipitation products, focusing on their ability to represent snowfall accumulation and distribution. Most of the study area is located north of $60^{\circ} \mathrm{N}$, where estimation of snowfall, in particular, is uncertain [19]; therefore, this assessment provides valuable information about the type of products that yield the best results. In particular, this study allowed us to assess different product types (gauge based, satellite, or reanalysis), different satellite measurement types (passive microwave vs infrared), and different undercatch correction factors applied to the gauge data (Fuchs or Legates). Furthermore, we assessed the consistency of snowfall and SWE data, as well as the impact of spatial scaling between the in situ observations and the coarse resolution precipitation products, using relatively high resolution $(4 \mathrm{~km})$ precipitation estimates from the National Centers for Environmental Prediction (NCEP) rescaled to multiple resolutions.

\section{Data and Method}

The datasets used in this study can be classified into three groups: in situ, satellite, and reanalysis products.

\subsection{In Situ Products}

The SNOTEL network is an automated system that has collected real-time in situ snowpack and other climatic data in the western U.S. and Alaska since 1981. Most SNOTEL stations provide daily and hourly measurements of snow water equivalent, precipitation, snow depth, air temperature, and sometimes other quantities, such as wind speed, relative humidity, and soil moisture. A standard SNOTEL sensor is configured with snow pillows and a precipitation gauge. The snow pillow contains an antifreeze solution and pressure is exerted once snow accumulates on the solution. The weight of snow is further converted into snow water equivalent by a manometer. The precipitation gauge is charged with an oil-antifreeze solution to reduce evaporation and freezing [33]. In this study, we used SWE measurements using snow pillows (hereafter referred to as SNOTELSWE) and precipitation measurements using precipitation gauges (hereafter referred to as SNOTEL-PG). The locations of SNOTELs used in this study are shown in Figure 1. The data can be retrieved from the government website of United States Department of Agriculture: https:/ / www.nrcs.usda.gov/wps/portal/wcc/home/snowClimateMonit oring/snowpack/ (accessed on 20 April 2021).

GPCC is a gridded-precipitation product over global land, excluding Antarctica, that interpolates station data from different rain gauge networks [34]. GPCC contains various products. Here we used two: (1) the latest Full Data Daily product (version 2020), which uses an enhanced quality control and interpolation scheme and the maximum number of available gauges (referred to here as GPCC); and (2) the monitoring product version 2020, which provides monthly values based on CF-F. Both products are available at $1^{\circ} \times 1^{\circ}$ resolution from 1982 to 2019 and can be obtained from: https: / / opendata.dwd.de/clim ate_environment/GPCC/html/download_gate.html (accessed on 20 April 2021). Two variations of GPCC were also produced in this study to assess which CF is more effective: GPCC-F that is obtained by applying CF-F from the monitoring product to GPCC Full data, 
and GPCC-L that uses CF-L (based on [10]) to correct GPCC. Note that GPCC does not use SNOTEL data, and so the GPCC and SNOTEL data are independent of each other.

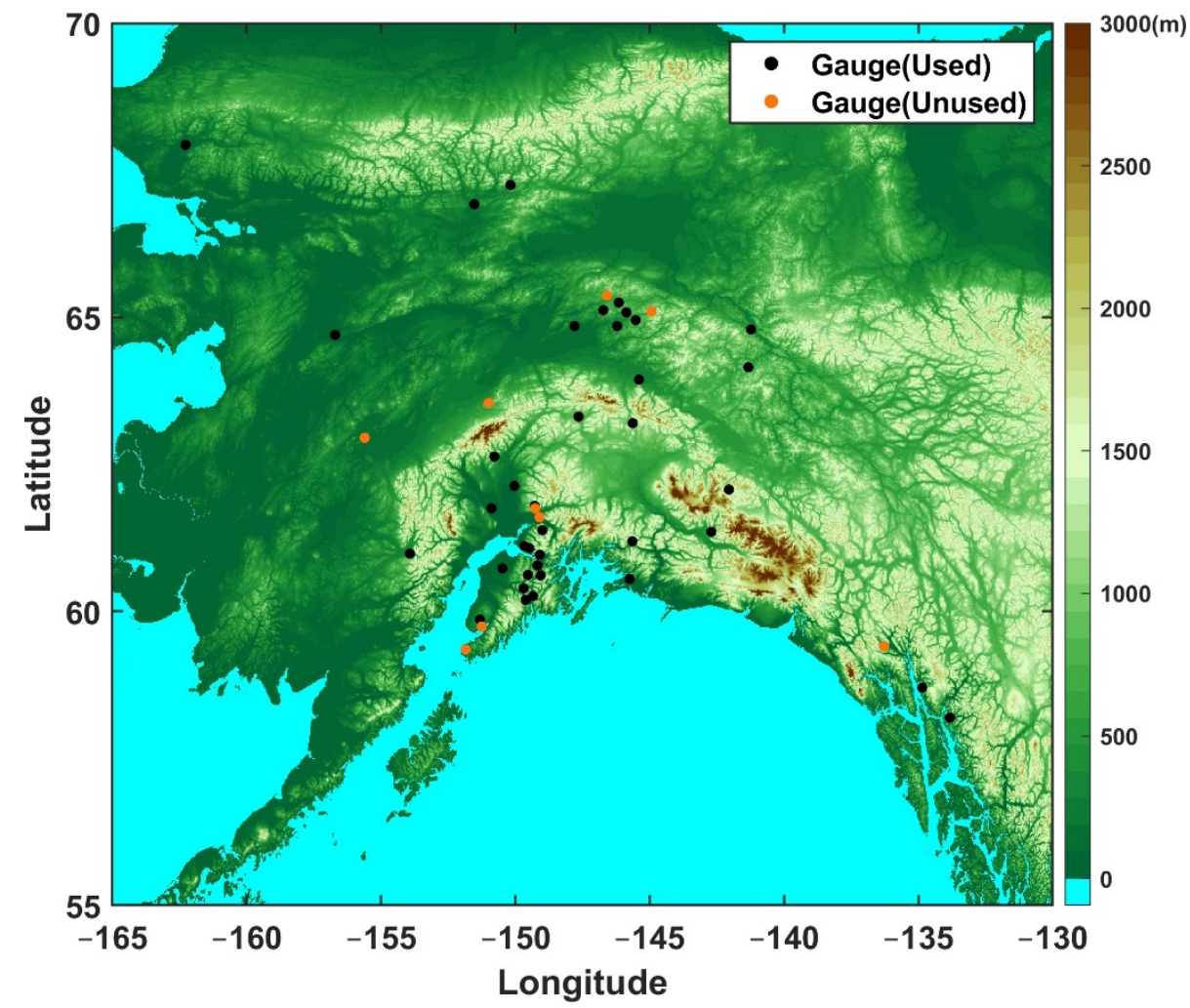

Figure 1. Location of SNOTEL stations used in this study, with the topography map in the background. The solid orange circles represent the location of SNOTEL stations not used, mainly due to an incomplete record. The red box indicates the SNOTEL station used as the example to illustrate the time series of snow and precipitation accumulation in Figure 2.

\subsection{Satellite Products}

GPCP is a widely used precipitation climatology product $[35,36]$ that utilizes precipitation estimates from both satellite and rain gauge data (through the GPCC product) after applying a gauge undercatch correction factor (CF-L). The latest version of the One-Degree Daily (1DD) product (GPCP V1.3) [20] was used in this study and has been available since 1996. GPCP's satellite precipitation estimates over land and ocean come from several space-borne sensors, but at high latitudes and near the poles they are mainly from IR sounders [37], specifically the Atmospheric Infrared Sounder (AIRS) after 2003. GPCP 1DD V1.3 can be obtained from http:/ / eagle1.umd.edu/GPCP_CDR/ (accessed on 20 April 2021).

AIRS is a hyperspectral resolution IR spectrometer on board the AQUA satellite and has been operational since 2002 [38]. The precipitation estimates from AIRS are based on the [21] algorithm and are available in a $1^{\circ} \times 1^{\circ}$ spatial grid at daily scale and can be retrieved from GES-DISC through https: / / disc.gsfc.nasa.gov/datasets/AIRS3SPD_7.0/s ummary (accessed on 20 April 2021).

The Integrated Multi-Satellite Retrievals for GPM High Quality data (IMERG-HQ) provides a blend of inter-calibrated passive microwave estimates at $0.1^{\circ} \times 0.1^{\circ}$ spatial and half-hour temporal resolutions, with global coverage since 2000 [19]. Here, the latest version of IMERG-HQ (Version 6) daily precipitation was used. The product is available from GES-DISC through https: / / disc.gsfc.nasa.gov/datasets/GPM_3IMERGDF_06/su mmary?keywords=imerg\%20v06 (accessed on 20 April 2021).

The Global Snow Monitoring for Climate Research (GlobSnow) funded by the European Space Agency (ESA) contains a long-term time series of snow water equivalents 
for terrestrial non-mountainous regions of the Northern Hemisphere, except for glaciers and ice sheets, from 1979 to the present. The SWE data is produced by integrating passive microwave radiometer data (SMMR, SSM/I, and SSMIS) and ground-based weather station data on a daily, weekly, and monthly basis. SWE product is projected to equal-area scalable earth grid (EASE-Grid), and the nominal resolution of each grid is $25 \mathrm{~km} \times 25 \mathrm{~km}$. GlobSnow is available at https: / / www.globsnow.info/se/ (accessed on 20 April 2021).

The AMSR-E/AMSR2 Unified Level-3 (L3) data provides SWE estimates that are derived from brightness temperature measurements from the Advanced Microwave Scanning Radiometer 2 (AMSR2) instrument on board the JAXA GCOM-W1 satellite, from July 2012 to the present. The SWE data are processed into EASE-Grid for both the Northern and Southern Hemispheres at daily scale and can be retrieved from https: / / nsidc.org/data/AU_DySno/versions/1 (accessed on 20 April 2021).

Sentinel-1 is a synthetic aperture radar (SAR) mission and is composed of a constellation of two satellites, Sentinel-1A and Sentinel-1B, producing continuous imagery at C-band (5.405 GHz) with different spatial resolutions (down to $5 \mathrm{~m}$ ) and coverages (up to $400 \mathrm{~km}$ ). The Sentinel-1 mission is designed to provide routine data and information products for operational applications, such as land surface mapping and natural disasters [39]. The snow depth retrieval of Sentinel-1 is suitable for analyses in mountainous environments because of its high resolution $(1 \mathrm{~km} \times 1 \mathrm{~km})$ and sensitivity to deep snow [40]. The data are available from September 2016 to April 2020 at a daily time scale and can be accessed from https://sentinel.esa.int/web/sentinel/sentinel-data-access (accessed on 20 April 2021).

\subsection{Reanalysis}

NCEP Stage IV is a gridded precipitation product based on a combination of about 150 radars, i.e., the NEXRAD, which refers to the Next Generation Weather Radar and corresponds to Weather Surveillance Radar-1988 Doppler [41] and numerous hourly gauge precipitation measurements over the CONUS. The merged precipitation is further processed and manually quality controlled at 12 River Forecast Centers. It is available on local $4 \mathrm{~km}$ polar-stereographic grids at hourly, 6-hourly, and 24-hourly (accumulated from the 6-hourly) resolutions [42]. The data availability is from December 2001 to February 2021 and has included Alaska and Puerto Rico stations since April 2017 (https: / / data.eol.ucar.edu/dataset/21.093 (accessed on 20 April 2021)) at 6-hourly and daily scales.

Modern-Era Retrospective Analysis for Research and Applications, Version 2 (MERRA2), is a popular reanalysis product that is available from 1980 at $0.5^{\circ} \times 0.625^{\circ}$ and hourly resolutions. MERRA2 substitutes the previous MERRA reanalysis with an upgraded data assimilation system to assimilate observations for retrospective analyses [43]. Here we used MERRA2 precipitation rate. The product can be obtained from the Goddard Earth Sciences Data and Information Services Center (GES DISC, https: / / disc.gsfc.nasa.gov /) and at https: / / disc.gsfc.nasa.gov / datasets?keywords=M2T1NXFLX.5.12.4\&page=1 (accessed on 20 April 2021).

ERA5 is the fifth generation ECMWF atmospheric reanalysis product, use the 4D-Var data assimilation technique [44], and is widely used by the community. ERA5 provides various meteorological parameters near the surface (in addition to multiple levels in the atmosphere) at relatively high resolution (i.e., $0.25^{\circ} \times 0.25^{\circ}$, hourly back to 1979 ). Here, we used precipitation rate, $2 \mathrm{~m}$ air temperature, and sublimation from ERA5. The ERA5 products can be obtained from https://www.ecmwf.int/en/research/climate-re analysis (accessed on 20 April 2021). Note that the precipitation phase of all satellite and reanalysis products is determined by $2 \mathrm{~m}$ air temperature (T2m), i.e., snowfall/precipitation when $\mathrm{T} 2 \mathrm{~m}$ is below / above $0{ }^{\circ} \mathrm{C}$. Satellite and reanalysis products have different spatial resolutions, and to tackle this issue, we upscaled all the gridded products (except for GPCP and GPCC) into a common daily $1^{\circ} \times 1^{\circ}$ resolution grid by applying an embedded interpolation function in MATLAB, which is consistent with the resolution of GPCP and GPCC. For grids that contain a SNOTEL site, the gridded data were compared to the 
SNOTEL-SWE and SNOTEL-PG measurements. For the assessment of snowfall, this analysis was limited to the snow accumulation period when surface air temperature was continuously less than $0{ }^{\circ} \mathrm{C}$, ensuring that all SNOTEL-PG measurements were of snowfall, and snow accumulation based on SNOTEL-SWE could be used as a surrogate for snowfall. Wind-induced snow transport processes are important source for shaping the spatial heterogeneity of snow distribution during winter, which further affects the estimation and evaluation of snowmelts, snow-deposition patterns, and critical storm events [13]. In addition to the SNOTEL data, we also used the NCEP stage IV product as an additional reference, to add insights into the scaling differences between the in situ SNOTEL data and the remote-sensing precipitation products. The study period covers 2017-2019, when Stage-IV data is available. By using two years of data, the snowfall accumulation of the precipitation products was compared near the end of the snow accumulation season (i.e., almost at peak SWE) at 39 SNOTEL sites.

\section{Results}

\subsection{Assessment of Snowfall and Precipitation Accumulation}

Figure 2 shows cumulative time-series of daily precipitation (dashed lines) and snowfall (solid lines shown in Figure 2a), along with the corresponding surface air temperature $(\mathrm{T} 2 \mathrm{~m})$ (Figure $2 \mathrm{~b}$ ) at one of the SNOTEL stations (shown in Figure 1 with a red box) for water year 2018 (October 2017-September 2018). The arrow shows the location of peak SWE. Precipitation is accumulated from the start to the end of the water year, but snowfall is only accumulated from when the $\mathrm{T} 2 \mathrm{~m}$ goes below $0{ }^{\circ} \mathrm{C}$ to when $\mathrm{T} 2 \mathrm{~m}$ goes above $0{ }^{\circ} \mathrm{C}$ or peak SWE, whichever comes earlier (note in Figure 2 that snowfall is not accumulated for any product after the time of peak SWE). As sublimation tends to be small in cold regions (i.e., as noted earlier, generally less than $3 \%$ of total precipitation accumulation during the winter based on ERA-5 reanalysis data; also demonstrated in [24]), precipitation and snow accumulation plots should be fairly comparable during the accumulation phase. Outside of this accumulation phase, precipitation often occurs as rainfall and generally has a higher accumulation slope than when all precipitation is snowfall (Figure 2a). Figure 2a suggests a few interesting points: (1) Almost all of the precipitation products (except for IMERG-HQ) capture major snowfall events (large positive increments in the accumulation plot); (2) IMERG-HQ tends to miss (or significantly underestimate) snowfall events, and its snowfall accumulation is very low (i.e., much smaller than the range identified by all of the other products), but it is more capable of capturing rainfall; (3) AIRS provides reasonable estimates of snowfall accumulation, but tends to overestimate precipitation accumulation toward the end of the water year; (4) SNOTEL-SWE and snowfall accumulation measured at the SNOTEL precipitation gauge (SNOTEL-PG) give comparable estimates of snow accumulation, though SNOTEL-SWE gives slightly higher estimates than SNOTEL-PG (this might have been due to minor gauge undercatch for SNOTEL-PG or slight overestimation by SNOTEL-SWE at this site); (5) At peak SWE, GPCC-L and GPCC-F (i.e., GPCC after applying gauge undercatch correction factors CF-L and CF-F, respectively) are closest to SNOTEL-SWE, followed by GPCP. GPCC without CFs produces the lowest accumulation among all of the products, except IMERG-HQ; (6) Most products (except for GPCC, IMERG-HQ, MERRA2, and ERA5) fall inside the snowfall accumulation range determined by SNOTEL-SWE and SNOTEL-PG; and (7) At the end of the water year, AIRS shows higher precipitation accumulation than the rest of the products; and IMERG-HQ, followed by GPCC (with no correction), shows the least precipitation accumulation. 
(a) Snow and Precipitaiton accumulation

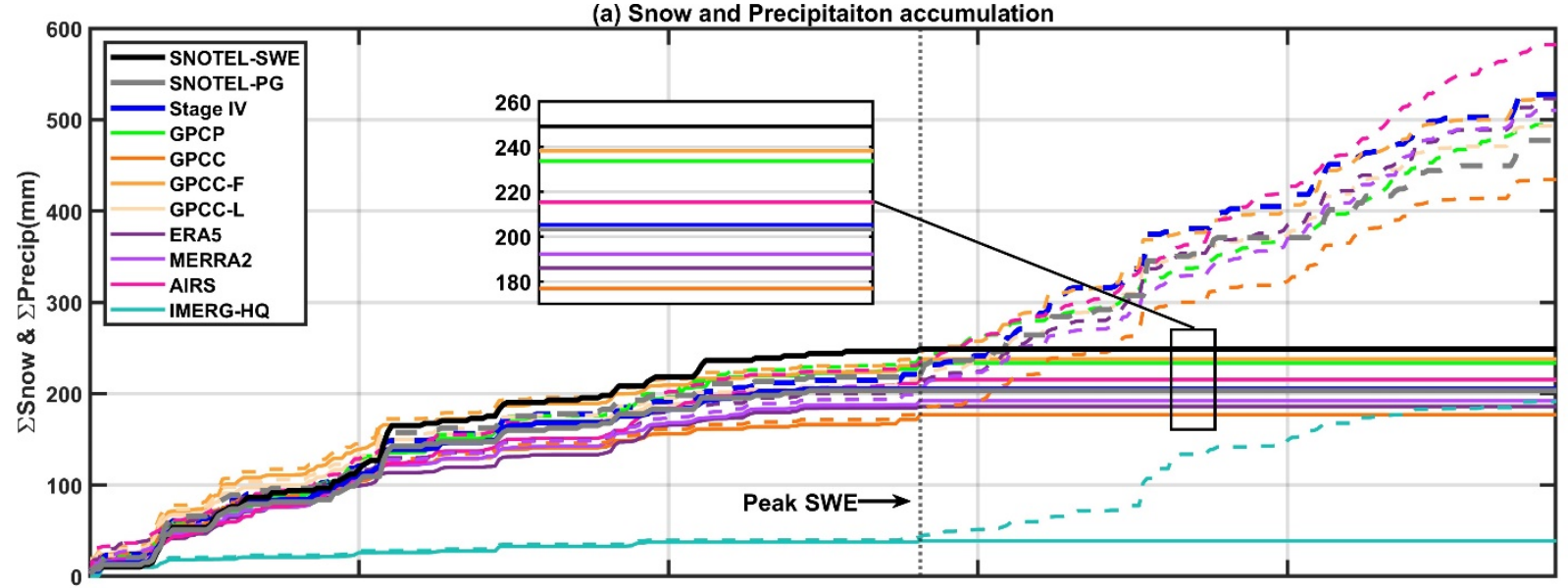

(b) Daily mean surface air temperature

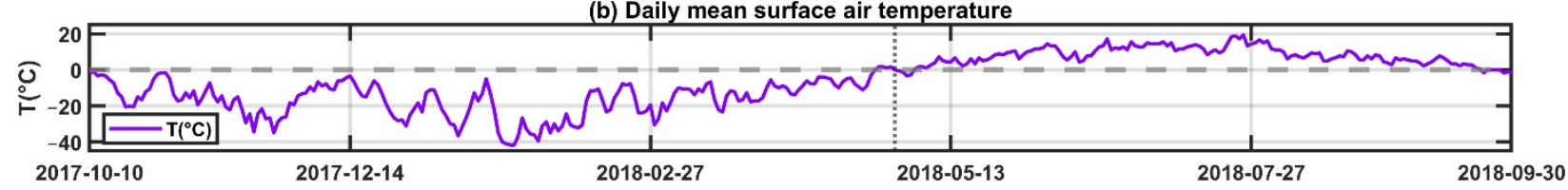

Figure 2. Cumulative time-series of (a) daily precipitation and SNOTEL-SWE, together with the corresponding (b) surface air temperature (T2m) at one of the SNOTEL stations (shown in Figure 1 with a red box) for the water year 2018. The solid and dashed lines represent snow and precipitation accumulation over the time period, respectively.

Figure 3 shows the mean (empty circles), median (the red line), as well as the 25th and the 75th percentile (boxes) of snowfall accumulation (prior to peak SWE and when $\mathrm{T} 2 \mathrm{~m}<0{ }^{\circ} \mathrm{C}$; Figure 3a), water year precipitation accumulation (Figure $3 \mathrm{~b}$ ), and their ratio (Figure 3c) for two water years (2018 and 2019). The 5th and the 95th percentile range are also shown with black dashed lines (extended from the boxes). Two versions of the Stage IV estimates are plotted: (1) the original $4 \mathrm{~km}$ resolution (Stage IV-4 km), and (2) $1^{\circ} \times 1^{\circ}$ resolution (Stage IV-1 deg), consistent with other products, in order to provide insight into the spatial scale differences that exist between SNOTEL and the gridded products. This is partly because differences in spatial scale can introduce errors into our comparative analysis, especially over topographically complex regions (see supplementary Figure S1). Similarly to what is shown in Figure 2, SNOTEL-PG is fairly consistent with SNOTEL-SWE in terms of snowfall accumulation across all sites (Figure 3a). GPCC-F, GPCC-L, AIRS, and Stage IV products fall within the range identified by either the mean or median of SNOTELPG and SNOTEL-SWE. The Stage IV products produce almost identical mean and median snowfall accumulation, but Stage IV— $4 \mathrm{~km}$ shows a larger range. They are also fairly consistent with the SNOTEL data (both SNOTEL-SWE and SNOTEL-PG). ERA5 shows the largest and IMERG-HQ shows the smallest snowfall accumulation among the products. For total precipitation at the end of water year (Figure 3b), Stage IV products, GPCP, GPCC-F-, GPCC-L, and AIRS show the closest values to SNOTEL-PG, both in terms of the median and mean values. ERA5 and MERRA2 tend to overestimate both snowfall and precipitation accumulation, while GPCC and IMERG-HQ tend to underestimate snowfall and precipitation accumulation. With respect to the ratio of snow accumulation over total precipitation (Figure 3c), GPCP has the highest mean and median ratios, and ERA5, and especially IMERG-HQ, have the lowest ratios compared to SNOTEL-PG. Similarly to what is shown in Figure 2, this demonstrates that IMERG-HQ has less skill for capturing snowfall than rainfall. 
(a)

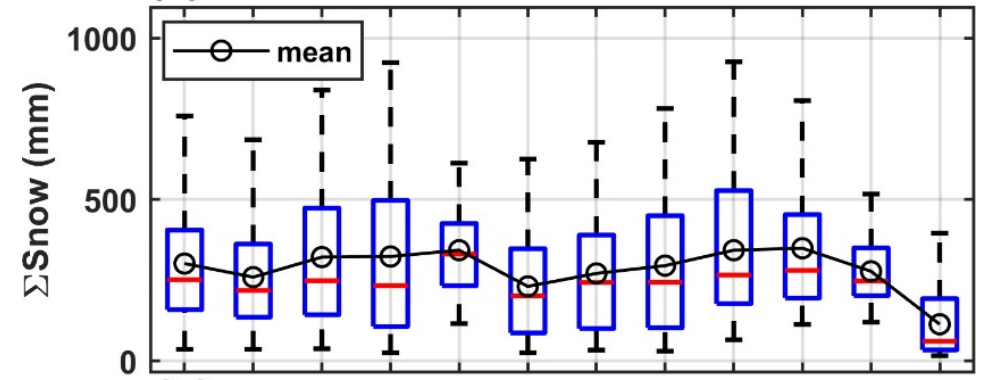

(b)
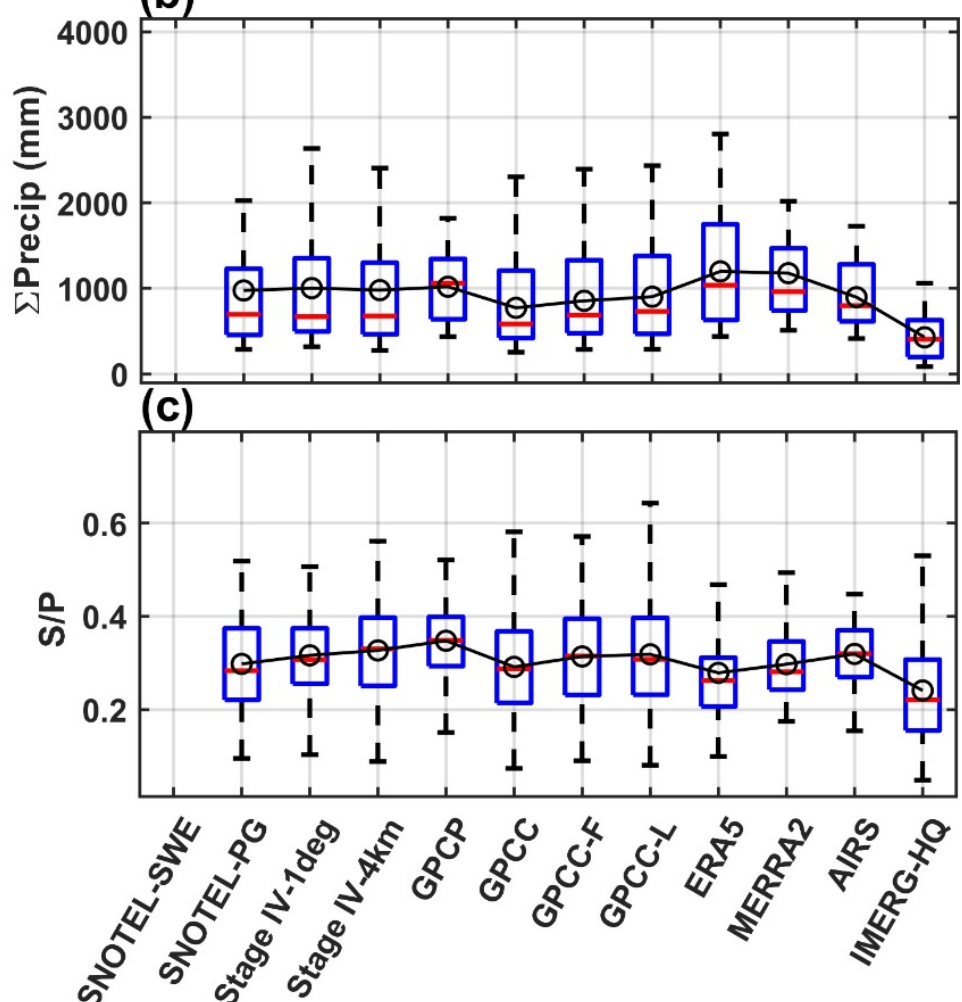

Figure 3. Comparison of the mean (empty circles), median (red line), and 25th and 75th percentiles of (a) snowfall during the accumulation phase, (b) water year total precipitation, and (c) their ratio using two water years (2018 and 2019).

Figure 4 shows Taylor plots with SNOTEL-SWE and SNOTEL-PG as reference for snowfall accumulation (Figure $4 a, b$ ) and SNOTEL-PG as reference for total precipitation (rainfall plus snowfall) accumulation (Figure 4c). For snowfall accumulation, Figure 4a,b suggest: (1) The choice of SNOTEL-SWE or SNOTEL-PG does not change the results, as the two products are very similar (e.g., the correlation coefficient $(C C)$ is about 0.97 when compared with each other; Figure $4 \mathrm{a}, \mathrm{b})$; (2) The Stage IV $4 \mathrm{~km}$ product has the highest CC ( 0.85) for snow accumulation, followed by the GPCC products, MERRA2, and Stage IV-1deg, which all show a CC around 0.7; (3) While correction factors are effective for reducing GPCC bias for snowfall accumulation (Figure 3), GPCC-F and GPCC-L show slightly lower CC than GPCC; GPCC-F also outperforms GPCC-L with respect to standard deviation and root mean square error (RMSE); (4) GPCP shows slightly lower CC ( 0.6) than GPCC products, probably because GPCP uses a combination of AIRS (CC $\sim 0.5)$ and GPCC-L (CC 0.7). ERA-5 also has a CC 0.6; and (5) While IMERG-HQ shows large underestimation of snowfall accumulation (Figure 3$)$, its CC ( 0.6) and RMSE are within the range of other products, suggesting that IMERG-HQ has skill for capturing the snowfall accumulation patterns, and that bias correction can improve IMERG-HQ. 
(a)

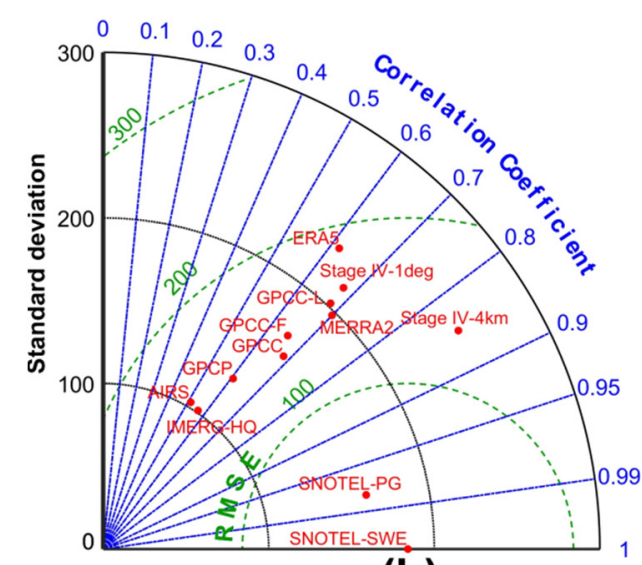

(b)

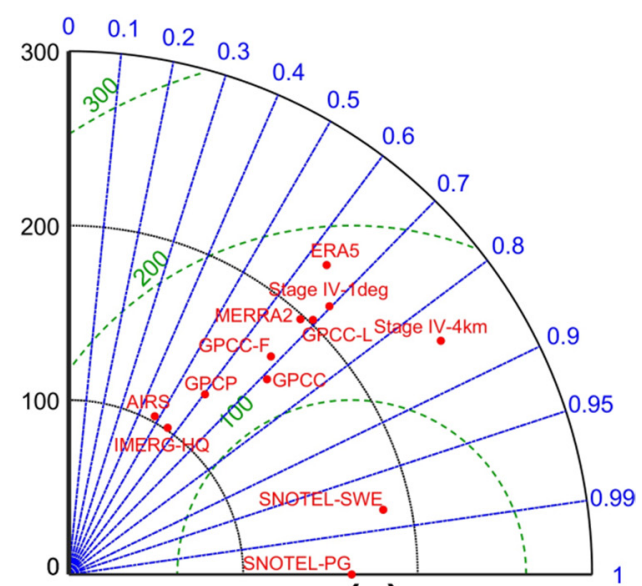

(c)

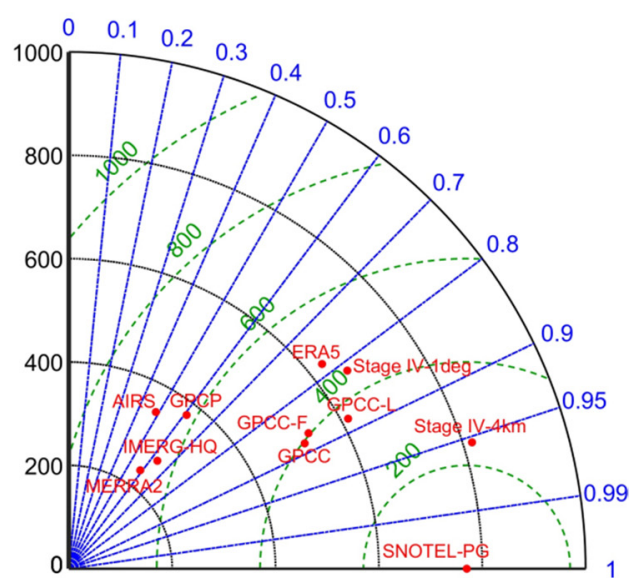

Figure 4. Taylor plots for snow accumulation with (a) SNOTEL-SWE and (b) SNOTEL-PG as references, respectively, and (c) SNOTEL-PG as a reference for precipitation accumulation.

For precipitation comparison, Figure 4c suggests: (1) Most of the products show equal or better CC for precipitation than snowfall accumulation; (2) Stage IV-4 km shows the best CC ( 0.95), followed by GPCC products and Stage IV-1 deg (which have CC between 0.8 and 0.9); (3) Unlike for snowfall accumulation, where MERRA2 outperforms ERA5, for precipitation accumulation, ERA5 has a higher CC ( 0.8), a closer standard deviation to that of SNOTEL-PG, and lower RMSE compared to MERRA2; and (4) IMERG-HQ's 
CC ( 0.6) is comparable to that of MERRA2 and GPCP, but GPCP shows better skill than IMERG-HQ and MERRA2 in terms of standard deviation and RMSE (Figure 4c).

SNOTEL-SWE, SNOTEL-PG, and Stage IV observations are fairly consistent, even considering scale differences between the in situ SNOTEL data and the gridded Stage IV data (see Figures 2 and 3), which suggests that they can be used to define 'observational' ranges for snowfall and precipitation accumulation (although SNOTEL-SWE can only be used to estimate snowfall). Figure 5 shows, for each SNOTEL station, which products fall within these observational ranges of snowfall (Figure 5a) and precipitation (Figure 5b) accumulation. Products that fall within these observational ranges are shown in white, while blue and red indicate which products under- or over-estimate snowfall and precipitation, with lighter (darker) colors showing closer (farther) distances to the observational ranges. For example, in Figure 5a for station 951, GPCC-F and ERA5 fall within the observational range; GPCC, GPCC-L, and IMERG-HQ are below the observational range (with IMERG-HQ being farthest from the range); and GPCP, AIRS, and MERRA2 are above the observational range (with MERRA2 being farthest from the range). Numbers on the right-side of the plots show, for each product, the number of cases that are within the observational range. Figure 5a shows that for snow accumulation, ERA5, MERRA2, GPCC-F, and GPCC-L have the highest number of 'hits' (white grids) inside the observational snow accumulation range, and IMERG-HQ has the least number of hits. For precipitation accumulation, GPCC-F has the highest number of hits, followed by ERA5 and MERRA2. Figure 5 also shows that GPCP, ERA5, MERRA2, and AIRS tend to overestimate snowfall and precipitation accumulation at most sites, while IMERG-HQ and GPCC tend to underestimate snowfall and precipitation accumulation, as can be seen by the dominant red and blue grids in their corresponding rows.

(a)

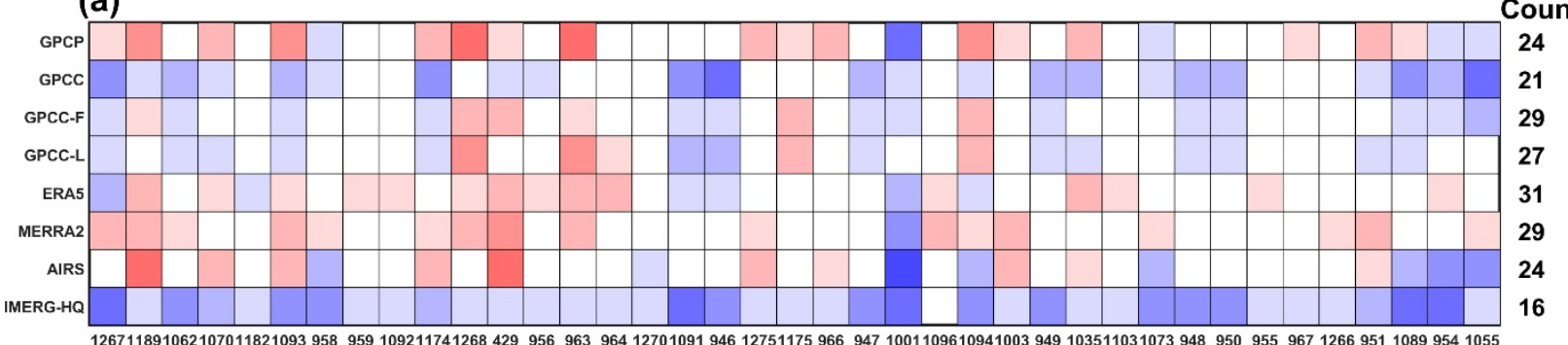

(b)
(b)

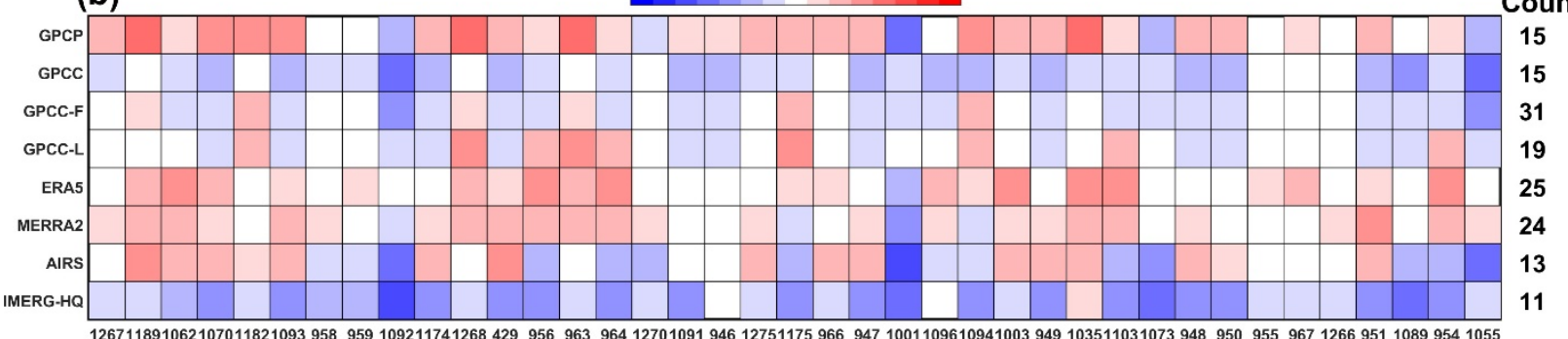

Figure 5. Comparison of snowfall and precipitation accumulation with the range defined by SNOTEL-PG, SNOTEL-SWE, and Stage IV for (a) snow accumulation and (b) precipitation accumulation at each SNOTEL site for water years 2018 and 2019. There are 39 SNOTEL sites in total. Numbers on the right sides of the plots indicate how often each product's snowfall or precipitation falls within the observational range.

\subsection{Assessment of SWE}

The analysis of SWE and snowfall accumulation at SNOTEL sites (SNOTEL-SWE and SNOTEL-PG) provide complementary information that adds valuable insights about the range of snowfall accumulation, as both measurements can be uncertain. Snowfall, measured using precipitation gauges, can be underestimated due to undercatch issues, and SWE accumulation can be affected by melting or sublimation, though these are often 
small during the snow accumulation phase in Alaska. We showed that the two estimates are also consistent with the corresponding values observed from Stage IV products at different scales. Together, these observational data can be used to assess several other precipitation products in Alaska, where satellite products typically have large errors in estimating snowfall, especially over snow and ice surfaces [19].

Owing to the lack of quality observation of snowfall, it would be useful to utilize other high quality observational products such as SWE, when and where possible. For a broader coverage, one has to rely on satellite based SWE observations outside the SNOTEL sites. Two popular operational satellite products for SWE are GlobSnow-2 and AMSR-E/AMSR2. While it has been found that AMSR products are not accurate for SWE estimation [45], GlobSnow-2 seems to provide reasonable estimates of SWE [46] for non-mountainous regions of the Northern Hemisphere. It goes back to 1979 by integrating in situ data with passive microwave radiometer data from various satellite instruments at daily, weekly, and monthly timescales.

Figure 6 compares SWE accumulation peaks from GlobSnow (Figure 6a) and AMSR-2 (Figure 6b) with the corresponding SNOTEL-SWE used in this study. GlobSnow and AMSR2 do not use SNOTEL data. GlobSnow shows a fairly good correlation with SNOTEL-SWE $(C C=0.72)$, with low bias, defined as the ratio of snowfall accumulation from GlobSnow over snow accumulation at SNOTEL-SWE (no bias is represented by 1). On the other hand, AMSR-2 shows low correlation, high RMSE, and significant underestimation compared to SNOTEL-SWE. The higher skill of GlobSnow compared to AMSR-2 is consistent with previous studies [47-49] and suggests that GlobSnow is more appropriate than AMSR-2 for SWE estimation. However, GlobSnow has no coverage over mountainous regions, which is a limiting factor. In addition, GlobSnow may underestimate deep snow (or high SWE; [50]) and overestimate shallow snow (or low SWE), as can be seen in Figure 6a.
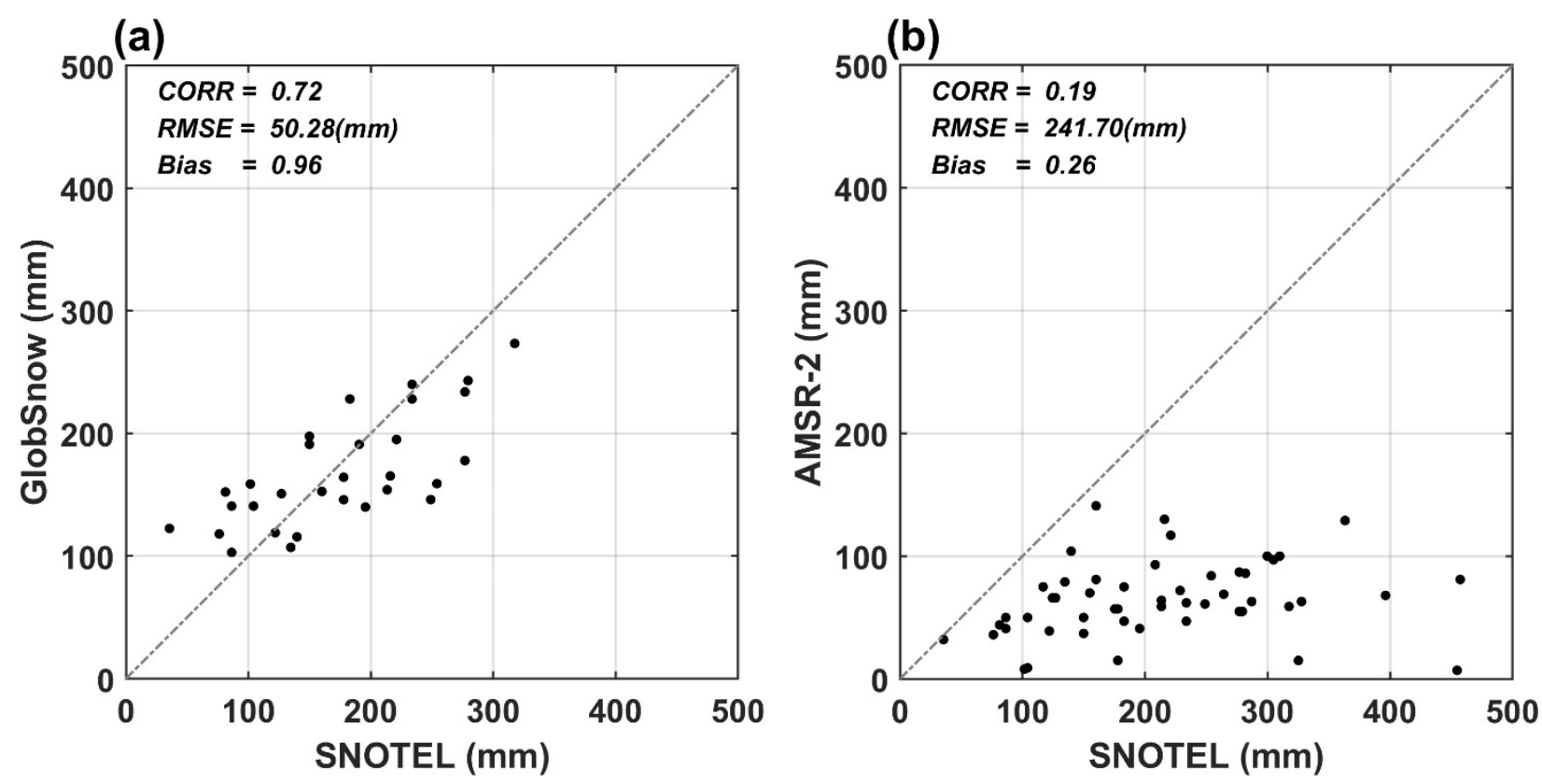

Figure 6. Comparison of SWE estimates between SNOTEL and (a) GlobSnow, and (b) AMSR-2 for water years 2018 and 2019. The black dots represent the common available SNOTEL sites with GlobSnow and AMSR-2, respectively.

For the deep snow cases and for observations over mountains, a potential alternative could be the use of the Sentinel-1 snow depth product, which has shown good skill in capturing deep snow over mountains [40]; although this method would have to deal with uncertainties in converting snow depth to SWE. Figure 7 shows an example of comparing snow depth during the snow accumulation phase from two SNOTEL sites (shown in rows) with that from Sentinel-1, GlobSnow, and AMSR-2, at the range of spatial resolutions 
from $0.25^{\circ}$ (corresponding to GlobSnow and AMSR-2) to $1 \mathrm{~km}$ offered by Sentinel-1 snow depth [40]. Snow depth from AMSR-E and GlobSnow was calculated using snow density determined at SNOTEL sites by dividing the measured snow depth by the measured SWE. Figure 7a shows that GlobSnow and Sentinel-1 are able to capture SNOTEL snow depth much better than AMSR-2, although GlobSnow tends to overestimate, and Sentinel-1 tends to underestimate the SNOTEL snow depth. Moving from $0.25^{\circ}$ to $1 \mathrm{~km}$ resolution, Sentinel1 shows a better match with SNOTEL near the peak of snow depth. The high spatial resolution of Sentinel-1 is valuable, because the estimates can be used at various spatial scales and can be compared with other products. In fact, by comparing the coincident snow depth observations from Sentinel-1 and SNOTEL, Figure 8 shows a better overall statistic for Sentinel-1 with the original resolution (i.e., $1 \mathrm{~km}$ ) than the coarser resolution of Sentinel- 1 at $0.1^{\circ}$ and $0.25^{\circ}$. However, it is important to note that Sentinel- 1 observations are not available every day, and the frequency of observation depends on location and overpass times, varying between daily and once every two weeks. This is the reason why in Figure 7 Sentinel-1 has a lower frequency of sampling compared to GlobSnow and AMSR-2, which provide daily estimates. Nonetheless, a combination of GlobSnow and Sentinel-1 observations provides opportunities to further assess snow accumulations over broad regions, including mountains. Such observations, together with snowfall estimates from space, can provide complementary information for further assessment of snow accumulation and monitoring snowpack, which is critical for water resources. For all of these estimates accurate quantification of errors can help determine which product, at which location and time, might be more trusted for providing snowfall-related information, so that individual or a combination of products can be used more effectively.

(a)

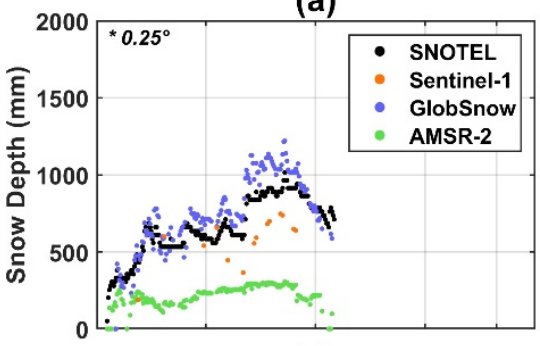

(d)

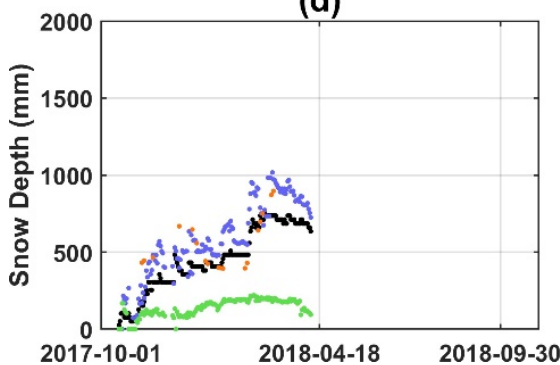

(b)

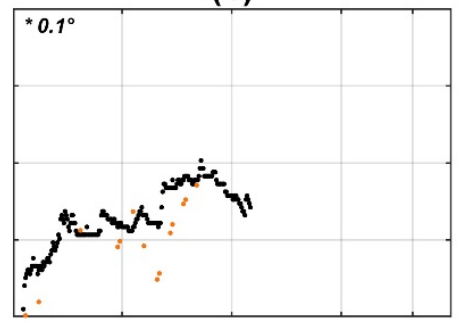

(e)

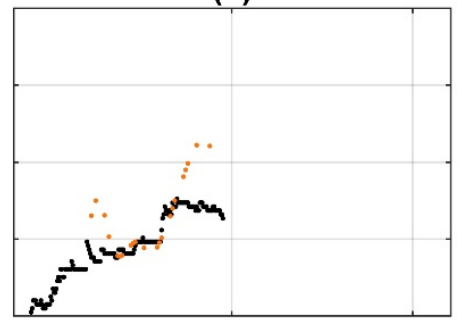

(c)

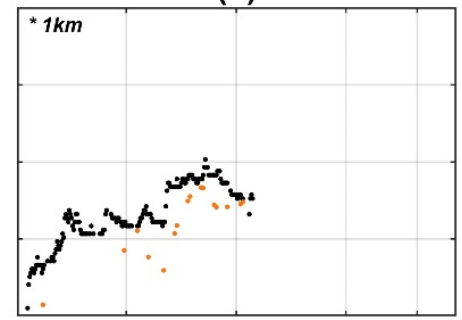

(f)

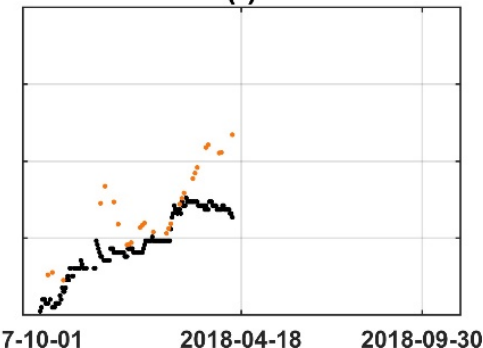

Figure 7. Comparison of snow depth during the snow accumulation phase from two SNOTEL sites (shown in rows (a-c, d-f)) with that from Sentinel-1, GlobSnow, and AMSR-2, at a range of spatial resolutions from $0.25^{\circ}$ (corresponding to GlobSnow and AMSR-2) to $1 \mathrm{~km}$, from Sentinel-1 snow depth product for the water year 2018. 
(a)

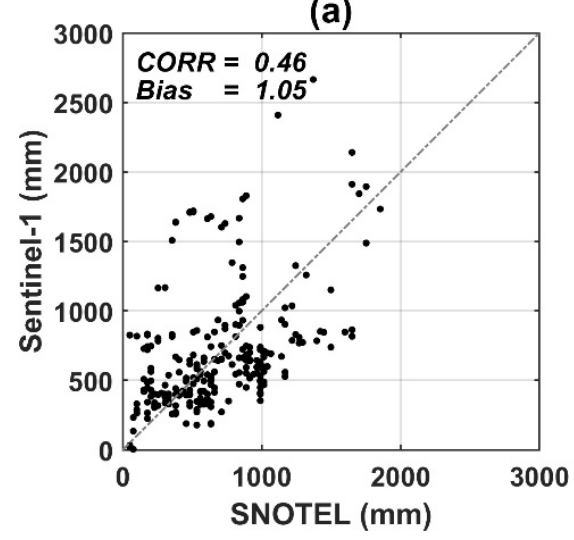

(b)

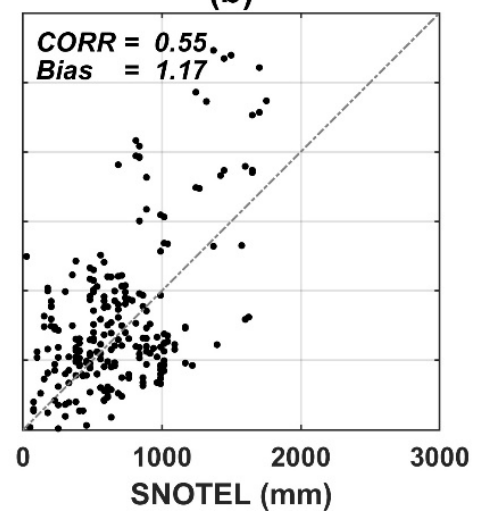

(c)

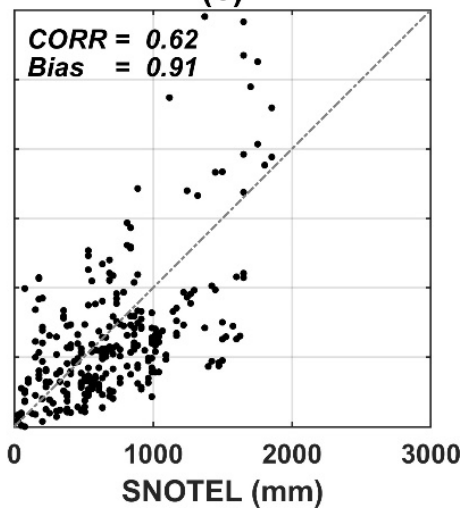

Figure 8. Comparing coincident snow depth observations from Sentinel-1 and SNOTEL in Alaska at various Sentinel-1 resolutions: (a) $0.25^{\circ}$, (b) $0.1^{\circ}$, and (c) $1 \mathrm{~km}$ for water year 2018. The black dots represent the common available SNOTEL sites with Sentinel-1.

\section{Concluding Remarks}

Here, we used combination of SNOTEL observations of daily SWE and snowfall to evaluate, not only their own consistency, but also various precipitation products. We found that snowfall estimates based on SWE and precipitation gauge data at SNOTEL sites are consistent, and together with the Stage IV-4 km product, can provide a range to assess other precipitation products. By comparing Stage IV-4 km with its scaled version at 1-degree resolution, it was found that the overall snowfall or precipitation bias is not much affected (Figure 3), but the CC is improved at higher resolution (Figure 4). By comparing the time series of snowfall and SWE accumulation, it was found that most of the products (except IMERG-HQ) can capture snowfall events (e.g., Figure 2); however, differences exist in their accumulation.

It was found that correction factors applied to GPCC are effective for improving the undercatch of GPCC gauges, especially for snowfall; with CF-F outperforming CF-L overall (Figure 5). However, no improvement in correlation is seen when correction factors are applied to GPCC. This is also the case for total precipitation, although GPCC products performed much better in capturing total precipitation than snow accumulation based on Taylor plots. This can be attributed to the better performance of rain gauges for capturing rainfall than snowfall. Overall, GPCP, ERA5, and MERRA2 seem to overestimate snow accumulation, while GPCC (without correction factors) and IMERG-HQ underestimate both snow and precipitation accumulation. The combined passive microwave product, IMERG-HQ, has the largest underestimation for snowfall, but it is able to capture the spatial pattern of snowfall similarly to some of the other products. This suggests that the passive microwave products can be improved substantially through bias correction. By comparison, AIRS (based on satellite IR data) performs acceptably in capturing mean precipitation, but tends to slightly overestimate both total precipitation and snowfall accumulation at most stations.

While this study utilized a combination of SWE and precipitation observations at several SNOTEL sites in Alaska to assess snowfall in the aforementioned precipitation products, the availability of such observations are limited globally. For example, observation networks that include automated measurements of both snow depth and SWE (similar to most SNOTEL stations) are limited to a few regions, such as to the western part of the North America, and primarily to the mountains. Therefore, it would be beneficial to combine remotely sensed estimates of snowfall with large scale SWE monitoring data to generate better estimates of snowfall. Among these products are GlobSnow (although it has gaps over mountains), the snow depth from Sentinel-1 that has shown skill for deep snow over mountainous regions, and other regional products (e.g., ASO or UA-SWE). Future improvements in the remote sensing of SWE and snow depth, as suggested by the recent 
national academy decadal survey report [51], together with improved sensors and retrieval algorithms for snowfall estimation should advance our capabilities to more accurately estimate snowfall features and uncertainties.

Supplementary Materials: The following are available online at https:/ / www.mdpi.com/article/1 $0.3390 / \mathrm{rs} 13152922 / \mathrm{s} 1$, Figure S1. Mean of Stage IV snowfall at spatial scale 0.04 degree.

Author Contributions: Conceptualization, Y.S., P.D.B. and A.B.; methodology, Y.S.; software, Y.S.; validation, Y.S., P.D.B. and A.B.; formal analysis, Y.S., P.D.B. and A.B.; investigation, Y.S.; resources, Y.S.; data curation, Y.S.; writing-original draft preparation, Y.S., M.R.E. and A.B.; writing-review and editing, Y.S. and M.R.E.; visualization, Y.S.; supervision, P.D.B. and A.B. All authors have read and agreed to the published version of the manuscript.

Funding: NASA MEaSUREs (NNH17ZDA001N-MEASURES) and NASA Weather and Atmospheric Dy-namics (NNH19ZDA001N-ATDM) grants.

Institutional Review Board Statement: Not applicable.

Informed Consent Statement: Not applicable.

Data Availability Statement: Publicly available datasets were analyzed in this study. This data can be found here: https://www.nrcs.usda.gov/wps/portal/wcc/home/snowClimateMonitoring/sn owpack/; https://opendata.dwd.de/climate_environment/GPCC/html/download_gate.html; http: / / eagle1.umd.edu/GPCP_CDR/; https:/ / disc.gsfc.nasa.gov/datasets / AIRS3SPD_7.0/summary; https:/ / disc.gsfc.nasa.gov/datasets/GPM_3IMERGDF_06/summary?keywords=imerg\%20v06; https://www.globsnow.info/se/; https://nsidc.org/data/AU_DySno/versions/1; https:/ /sent inel.esa.int/web/sentinel/sentinel-data-access; https:/ / data.eol.ucar.edu/dataset/21.093; https: / / disc.gsfc.nasa.gov / datasets?keywords=M2T1NXFLX.5.12.4\&page=1; https: / / www.ecmwf.int / en/research/climate-reanalysis (all accessed on 4 June 2021). The data presented in this study are available on request from the corresponding author. The data are not publicly available due to privacy. Data sharing not applicable. No new data were created or analyzed in this study. Data sharing is not applicable to this article. Data is contained within the article or supplementary material.

Acknowledgments: This study was performed mainly in the University of Arizona. Financial support was made available from NASA MEaSUREs (NNH17ZDA001N-MEASURES) and NASA Weather and Atmospheric Dynamics (NNH19ZDA001N-ATDM) grants.

Conflicts of Interest: The authors declare no conflict of interest.

\section{References}

1. Barnett, T.P.; Adam, J.C.; Lettenmaier, D.P. Potential impacts of a warming climate on water availability in snow-dominated regions. Nature 2005, 438, 303-309. [CrossRef]

2. Arabzadeh, A.; Ehsani, M.R.; Guan, B.; Heflin, S.; Behrangi, A. Global intercomparison of atmospheric rivers precipitation in remote sensing and reanalysis products. J. Geophys. Res. Atmos. 2020, 125, e2020JD033021. [CrossRef]

3. Kunkel, K.E.; Robinson, D.A.; Champion, S.; Yin, X.; Estilow, T.; Frankson, R.M. Trends and Extremes in Northern Hemisphere Snow Characteristics. Curr. Clim. Chang. Rep. 2016, 2, 65-73. [CrossRef]

4. Zeng, X.; Broxton, P.; Dawson, N. Snowpack Change From 1982 to 2016 Over Conterminous United States. Geophys. Res. Lett. 2018, 45, 12940-12947. [CrossRef]

5. Liu, G. A Database of Microwave Single-Scattering Properties for Nonspherical Ice Particles. Bull. Am. Meteorol. Soc. 2008, 89, 1563-1570. [CrossRef]

6. Levizzani, V.; Laviola, S.; Cattani, E. Detection and measurement of snowfall from space. Remote Sens. 2011, 3, 145-166. [CrossRef]

7. Behrangi, A.; Stephens, G.; Adler, R.F.; Huffman, G.J.; Lambrigtsen, B.; Lebsock, M. An Update on the Oceanic Precipitation Rate and Its Zonal Distribution in Light of Advanced Observations from Space. J. Clim. 2014, 27, 3957-3965. [CrossRef]

8. Fuchs, T.; Rapp, J.; Rubel, F.; Rudolf, B. Correction of synoptic precipitation observations due to systematic measuring errors with special regard to precipitation phases. Phys. Chem. Earth Part B Hydrol. Ocean. Atmos. 2001, 26, 689-693. [CrossRef]

9. Goodison, B.E.; Louie, P.Y.T.; Yang, D. WMO Solid Precipitation Measurement Intercomparison; World Meteorological Organization: Geneva, Switzerland, 1998.

10. Legates, D.R.; Willmott, C.J. Mean seasonal and spatial variability in gauge-corrected, global precipitation. Int. J. Climatol. 1990, 10, 111-127. [CrossRef]

11. Yang, D.; Ohata, T. A Bias-Corrected Siberian Regional Precipitation Climatology. J. Hydrometeorol. 2001, 2, 122-139. [CrossRef]

12. Mott, R.; Schirmer, M.; Bavay, M.; Grünewald, T.; Lehning, M. Understanding snow-transport processes shaping the mountain snow-cover. Cryosphere 2010, 4, 545-559. [CrossRef] 
13. Mott, R.; Schirmer, M.; Lehning, M. Scaling properties of wind and snow depth distribution in an Alpine catchment. J. Geophys. Res. Atmos. 2011, 116. [CrossRef]

14. Vionnet, V.; Martin, E.; Masson, V.; Guyomarc'h, G.; Naaim-Bouvet, F.; Prokop, A.; Durand, Y.; Lac, C. Simulation of wind-induced snow transport and sublimation in alpine terrain using a fully coupled snowpack/atmosphere model. Cryosphere 2014, 8, 395-415. [CrossRef]

15. Behrangi, A.; Andreadis, K.; Fisher, J.B.; Turk, F.J.; Granger, S.; Painter, T.; Das, N. Satellite-Based Precipitation Estimation and Its Application for Streamflow Prediction over Mountainous Western U.S. Basins. J. Appl. Meteorol. Climatol. 2014, 53, $2823-2842$. [CrossRef]

16. Behrangi, A.; Tian, Y.; Lambrigtsen, B.H.; Stephens, G.L. What does CloudSat reveal about global land precipitation detection by other spaceborne sensors? Water Resour. Res. 2014, 50, 4893-4905. [CrossRef]

17. Behrangi, A.; Christensen, M.; Richardson, M.; Lebsock, M.; Stephens, G.; Huffman, G.J.; Bolvin, D.; Adler, R.F.; Gardner, A.; Lambrigtsen, B.; et al. Status of high-latitude precipitation estimates from observations and reanalyses. J. Geophys. Res. Atmos. 2016, 121, 4468-4486. [CrossRef]

18. Skofronick-Jackson, G.; Petersen, W.A.; Berg, W.; Kidd, C.; Stocker, E.F.; Kirschbaum, D.B.; Kakar, R.; Braun, S.A.; Huffman, G.J.; Iguchi, T. The Global Precipitation Measurement (GPM) mission for science and society. Bull. Am. Meteorol. Soc. 2017, 98, 1679-1695. [CrossRef]

19. Huffman, G.J.; Bolvin, D.T.; Braithwaite, D.; Hsu, K.L.; Joyce, R.J.; Kidd, C.; Nelkin, E.J.; Sorooshian, S.; Stocker, E.F.; Tan, J.; et al. Integrated Multi-satellite Retrievals for the Global Precipitation Measurement (GPM) Mission (IMERG). In Advances in Global Change Research; Springer: Berlin, Germany, 2020; Volume 67, pp. 343-353.

20. Adler, R.F.; Gu, G.; Sapiano, M.; Wang, J.-J.; Huffman, G.J. Global Precipitation: Means, Variations and Trends During the Satellite Era (1979-2014). Surv. Geophys. 2017, 38, 679-699. [CrossRef]

21. Susskind, J.; Piraino, P.; Rokke, L.; Iredell, L.; Mehta, A. Characteristics of the TOVS Pathfinder Path A dataset. Bull. Am. Meteorol. Soc. 1997, 78, 1449-1472. [CrossRef]

22. Adhikari, A.; Ehsani, M.R.; Song, Y.; Behrangi, A. Comparative Assessment of Snowfall Retrieval From Microwave Humidity Sounders Using Machine Learning Methods. Earth Sp. Sci. 2020, 7, e2020EA001357. [CrossRef]

23. Ehsani, M.R.; Behrangi, A.; Adhikari, A.; Song, Y.; Huffman, G.J.; Adler, R.F.; Bolvin, D.T.; Nelkin, E.J. Assessment of the Advanced Very High-Resolution Radiometer (AVHRR) for Snowfall Retrieval in High Latitudes Using CloudSat and Machine Learning. J. Hydrometeorol. 2021, 22, 1591-1608.

24. Behrangi, A.; Gardner, A.; Reager, J.T.; Fisher, J.B.; Yang, D.; Huffman, G.J.; Adler, R.F. Using GRACE to Estitmate Snowfall Accumulation and Assess Gauge Undercatch Corrections in High Latitudes. J. Clim. 2018, 31, 8689-8704. [CrossRef]

25. Schneider, U.; Finger, P.; Meyer-Christoffer, A.; Rustemeier, E.; Ziese, M.; Becker, A. Evaluating the Hydrological Cycle over Land Using the Newly-Corrected Precipitation Climatology from the Global Precipitation Climatology Centre (GPCC). Atmos. 2017, 8, 52. [CrossRef]

26. Behrangi, A.; Singh, A.; Song, Y.; Panahi, M. Assessing Gauge Undercatch Correction in Arctic Basins in Light of GRACE Observations. Geophys. Res. Lett. 2019, 46, 11358-11366. [CrossRef]

27. Larsen, C.F.; Motyka, R.J.; Freymueller, J.T.; Echelmeyer, K.A.; Ivins, E.R. Rapid uplift of southern Alaska caused by recent ice loss. Geophys. J. Int. 2004, 158, 1118-1133. [CrossRef]

28. Behrangi, A.; Bormann, K.J.; Painter, T.H. Using the Airborne Snow Observatory to Assess Remotely Sensed Snowfall Products in the California Sierra Nevada. Water Resour. Res. 2018, 54, 7331-7346. [CrossRef]

29. Painter, T.H.; Berisford, D.F.; Boardman, J.W.; Bormann, K.J.; Deems, J.S.; Gehrke, F.; Hedrick, A.; Joyce, M.; Laidlaw, R.; Marks, D. The Airborne Snow Observatory: Fusion of scanning lidar, imaging spectrometer, and physically-based modeling for mapping snow water equivalent and snow albedo. Remote Sens. Environ. 2016, 184, 139-152. [CrossRef]

30. Panahi, M.; Behrangi, A. Comparative Analysis of Snowfall Accumulation and Gauge Undercatch Correction Factors from Diverse Data Sets: In Situ, Satellite, and Reanalysis. Asia-Pacific J. Atmos. Sci. 2019. [CrossRef]

31. Broxton, P.D.; Zeng, X.; Dawson, N. Why do global reanalyses and land data assimilation products underestimate snow water equivalent? J. Hydrometeorol. 2016, 17, 2743-2761. [CrossRef]

32. Gonzalez, R.; Kummerow, C.D. AMSR-E Snow: Can Snowfall Help Improve SWE Estimates? J. Hydrometeorol. 2020, 21, 2551-2564. [CrossRef]

33. Serreze, M.C.; Clark, M.P.; Armstrong, R.L.; Mcginnis, A.; Pulwarty, R.S. Characteristics of the western United States snowpack from snowpack telemetry (SNOTEL) data. Water Resour. Res. 1999, 35, 2145-2160. [CrossRef]

34. Becker, A.; Finger, P.; Meyer-Christoffer, A.; Rudolf, B.; Schamm, K.; Schneider, U.; Ziese, M. A description of the global landsurface precipitation data products of the Global Precipitation Climatology Centre with sample applications including centennial (trend) analysis from 1901-present. Earth Syst. Sci. Data 2013, 5, 71-99. [CrossRef]

35. Adler, R.F.; Huffman, G.J.; Chang, A.; Ferraro, R.; Xie, P.-P.; Janowiak, J.; Rudolf, B.; Schneider, U.; Curtis, S.; Bolvin, D.; et al. The Version-2 Global Precipitation Climatology Project (GPCP) Monthly Precipitation Analysis (1979-Present). J. Hydrometeorol. 2003, 4, 1147-1167. [CrossRef]

36. Huffman, G.J.; Adler, R.F.; Bolvin, D.T.; Gu, G. Improving the global precipitation record: GPCP Version 2.1. Geophys. Res. Lett. 2009, 36. [CrossRef] 
37. Huffman, G.J.; Adler, R.F.; Morrissey, M.M.; Bolvin, D.T.; Curtis, S.; Joyce, R.; McGavock, B.; Susskind, J. Global Precipitation at One-Degree Daily Resolution from Multisatellite Observations. J. Hydrometeorol. 2001, 2, 36-50. [CrossRef]

38. Aumann, H.H.; Chahine, M.T.; Gautier, C.; Goldberg, M.D.; Kalnay, E.; McMillin, L.M.; Revercomb, H.; Rosenkranz, P.W.; Smith, W.L.; Staelin, D.H.; et al. AIRS/AMSU/HSB on the aqua mission: Design, science objectives, data products, and processing systems. IEEE Trans. Geosci. Remote Sens. 2003, 41, 253-263. [CrossRef]

39. Geudtner, D.; Torres, R.; Snoeij, P.; Davidson, M.; Rommen, B. Sentinel-1 System capabilities and applications. In Proceedings of the 2014 IEEE Geoscience and Remote Sensing Symposium, Quebec City, QC, USA, 13-18 July 2014; pp. 1457-1460.

40. Lievens, H.; Demuzere, M.; Marshall, H.; Reichle, R.H.; Brucker, L.; Brangers, I.; de Rosnay, P.; Dumont, M.; Girotto, M.; Immerzeel, W.W.; et al. Snow depth variability in the Northern Hemisphere mountains observed from space. Nat. Commun. 2019, 1-12. [CrossRef]

41. Fulton, R.A.; Breidenbach, J.P.; Seo, D.-J.; Miller, D.A.; O'Bannon, T. The WSR-88D rainfall algorithm. Weather Forecast. 1998, 13, 377-395. [CrossRef]

42. Nelson, B.R.; Prat, O.P.; Seo, D.J.; Habib, E. Assessment and implications of NCEP stage IV quantitative precipitation estimates for product intercomparisons. Weather Forecast. 2016, 31, 371-394. [CrossRef]

43. Gelaro, R.; McCarty, W.; Suárez, M.J.; Todling, R.; Molod, A.; Takacs, L.; Randles, C.A.; Darmenov, A.; Bosilovich, M.G.; Reichle, R.; et al. The Modern-Era Retrospective Analysis for Research and Applications, Version 2 (MERRA-2). J. Clim. 2017, 30, 5419-5454. [CrossRef]

44. Hersbach, H. The ERA5 Atmospheric Reanalysis. In Proceedings of the AGU Fall Meeting Abstracts; American Geophysical Union: Washington, DC, USA, 2016.

45. Dawson, N.; Broxton, P.; Zeng, X. Evaluation of remotely sensed snow water equivalent and snow cover extent over the contiguous United States. J. Hydrometeorol. 2018, 19, 1777-1791. [CrossRef]

46. Luojus, K.; Pulliainen, J.; Takala, M.; Lemmetyinen, J.; Smolander, T.; Derksen, C. The GlobSnow Snow Water Equivalent Product. In Proceedings of the SnowPEX ISSPI-1, College Park, MD, USA, 22 July 2014.

47. Hancock, S.; Baxter, R.; Evans, J.; Huntley, B. Evaluating global snow water equivalent products for testing land surface models. Remote Sens. Environ. 2013, 128, 107-117. [CrossRef]

48. Schroeder, R.; Jacobs, J.M.; Cho, E.; Olheiser, C.M.; DeWeese, M.M.; Connelly, B.A.; Cosh, M.H.; Jia, X.; Vuyovich, C.M.; Tuttle, S.E. Comparison of Satellite Passive Microwave with Modeled Snow Water Equivalent Estimates in the Red River of the North Basin. IEEE J. Sel. Top. Appl. Earth Obs. Remote Sens. 2019, 12, 3233-3246. [CrossRef]

49. Yang, J.W.; Jiang, L.M.; Lemmetyinen, J.; Luojus, K.; Takala, M.; Wu, S.L.; Pan, J.M. Validation of remotely sensed estimates of snow water equivalent using multiple reference datasets from the middle and high latitudes of China. J. Hydrol. 2020, 590, 125499. [CrossRef]

50. Luojus, K.; Pulliainen, J.; Takala, M.; Lemmetyinen, J.; Kangwa, M.; Eskelinen, M.; Metsämäki, S.; Solberg, R.; Salberg, A.B.; Bippus, G. GlobSnow2-Final Report; Global Snow Monitoring for Climate Research, European Space Agency: Paris, France, 2014.

51. Board, S.S.; National Academies of Sciences, Engineering, and Medicine. Thriving on Our Changing Planet: A Decadal Strategy for Earth Observation from Space; The National Academies Press: Washington, DC, USA, 2018; ISBN 978-0-309-46757-5. 